\title{
QUALITY INDEX OF MULTI-DISC GRINDING PROCESS OF GRAINY BIOMASS
}

doi: 10.2478/cqpi-2019-0068

Date of submission of the article to the Editor: 06/05/2019

Date of acceptance of the article by the Editor: 28/05/2019

\author{
Weronika Kruszelnicka ${ }^{1}$ - orcid id: 0000-0002-9909-5112 \\ Adam Idzikowski ${ }^{2}$ - orcid id: 0000-0003-1178-8721 \\ Katarzyna Markowska ${ }^{3}$ - orcid id: 0000-0003-2184-1995 \\ Robert Kasner ${ }^{1}$ - orcid id: 0000-0001-6866-4741 \\ 1 University of Science and Technology in Bydgoszcz - Poland \\ ${ }^{2}$ Czestochowa University of Technology - Poland \\ ${ }^{3}$ Silesian University of Technology - Poland
}

\begin{abstract}
The main aim of the grinding process is size reduction. For such formulated purpose of grinding, the particles dimensions after grinding process are the major quality determinant indicated in many works concerning size reduction. In this paper original quality index integrating size reduction and energy consumption in the grinding process was proposed. The aim of the study is to create method for grinding process quality assessment. The problem was formulated as a question: (1) is it possible to create mathematical description of grinding process quality? (2) what grinding parameters influence on the grinding quality index? To resolve the problem, original quality index was developed and experiment on a multi-disc mill was conducted. On the basis of obtained results it was found that discs angular speed affects the grinding process quality.
\end{abstract}

Keywords: grinding, quality index, size reduction, granular biomass

\section{INTRODUCTION}

The term "quality", defined by Plato as a certain degree of perfection, is most often applied to products and services in terms of the level of meeting the customers and consumers needs. Quality criteria, that allow to compare and evaluate processes and products, are certain specific features or sets of features that are measurable, comparable or verifiable (Kolman, 2003; Kruszelnicka, 2018; Kruszelnicka et al., 2018).

The measurable quality criteria are mainly used in the comparative, scalar assessment of technology, services and the environment condition (Djekic et al., 2018; Chen et al., 2019; Lasisi and Attoh-Okine, 2018; Coronado-Mendoza et al., 2018; Kruszelnicka et al., 2019). D. Schwechten and G.H. Milburn (Schwechten and Milburn, 1990) as the grinding process quality criterion accepted the qualitative parameters of the product, and more precisely the size of the particles after 


\section{$\underline{504}$}

comminution. Similarly J. Hu et al. (Hu et al., 2012) used the quality parameters of the product to evaluate the process of grinding green tea leaves. The granulometric distribution for assessing the quality of grinding was also used in paper (Lee et al., 2017; Flizikowski et al., 2019; Tomporowski et al., 2017). In turn O. Williams et al. assessed the product quality with use particle size and shape distribution indexes (Williams et al., 2017).

For the grinding process, the essential criterion of process quality due to its purpose, is a fragmentation degree, which in general can be defined as the quotient of the characteristic feed dimension and the characteristic size of the particles after grinding (Mi et al., 2015; Tomporowski et al., 2018).

In few works quality indicators covering not only product properties, but also process parameters have been introduced. For example Seifoddini and Djassemi have developed a quality assessment index of manufacturing processes in terms of reliability and performance (Seifoddini and Djassemi, 2001). Other indicator including many different factors was developed by Albuquerque et al. (Albuquerque et al., 2010). This indicator included quality parameters of the granulate (product of granulation process) and process parameters such as: air pressure, air share coefficient. In paper (Dal-Pastro et. al., 2015) latent variable modeling techniques were used to combine process parameters and grain properties with the quality of the final product. On the basis of experimental data, it was shown how the use of models in their direct form allows for a better understanding of the process and prediction of product quality based on process settings and grain properties.

Less important from the point of view of the grinding purpose are comparable quality criteria, difficult to describe using mathematical models, enabling the assessment based on a comparison with the standards, patterns. They include functionality, reliability, ergonomics, eco-friendliness, aesthetics, technological ability, compliance with standards, labor consumption, material consumption (Przystupa et at., 2013; Łunarski, 2012; Przystupa, 2010).

On the basis of the analysis of the state of the art and technology, it is stated that up to now no effective quality index of the grinding process, that captures the parameters of the product and the process, has been developed. In the view of the above the aim of the study is to create method for assessment grinding process quality. The problem was formulated as a question: (1) is it possible to create mathematical description of grinding process quality? (2) what grinding parameters influence on the grinding quality index? To resolve the problem, original quality index was developed and experiment on a multi-disc mill was conducted.

\section{MATHERIALS AND METHODS}

\subsection{Quality index}

To describe the multi-disc grinding process quality by mathematical models, the relation between grinding effects ie. material size reduction and energy parameters were defined as:

$$
I_{Q}=\frac{\Delta S_{r}}{E_{C}}
$$

where: $\Delta S_{r}-$ size reduction of grinded material characteristic dimension [mm], $E_{c}-$ energy consumed in grinding process of $1 \mathrm{~kg}$ of material [kWh].

Size reduction of grinded material characteristic dimension is described as follows: 


$$
\Delta S_{r}=\bar{D}-\bar{d}
$$

wherein: $\bar{D}$ - average feed size determined on the basis of granulometric analysis [mm], $\bar{d}$ - average particle size after grinding determined on the basis of granulometric analysis [mm].

The feed material average dimension $\bar{D}$ is determined during the sieve analysis from the dependence:

$$
\bar{D}=\sum_{i=1}^{n} D_{i} \cdot Q_{i}
$$

where: $D_{i}$ - average grains size of $i$-th size class for feed material [mm], $Q_{i}-$ share of feed material particles for $i$-th size class,

In turn average dimension of product particles $\bar{d}$ is defined as:

$$
\bar{d}=\sum_{i=1}^{n} d_{i} \cdot q_{i}
$$

where: $d_{i}$ - average grains size of $i$-th size class for material after grinding [mm], $q_{i}-$ share of material particles after grinding for $i$-th size class,

Energy consumed in grinding process of $1 \mathrm{~kg}$ of material can be calculated on the basis of power measurement results and the formula:

$$
E_{c}=\frac{\sum_{k=1}^{m} N_{k} \cdot t_{k}}{3600}
$$

where: $N_{k}$ - power measured at sampling time $t_{k}[\mathrm{~kW}], t_{k}$ - sampling time [s].

Including in equation (1) the dependences (2), (3), (4) and (5), the equation takes form:

$$
I_{Q}=\frac{\bar{D}-\bar{d}}{E_{C}}=\frac{\sum_{i=1}^{n} D_{i} \cdot Q_{i}-\sum_{i=1}^{n} d_{i} \cdot q_{i}}{\frac{\sum_{k=1}^{m} N_{k} \cdot t_{k}}{3600}}
$$

For known $\bar{D}$ and for the postulated state, in which $\bar{d} \rightarrow 0$, then $\Delta S_{r} \rightarrow \bar{D}$ and assuming that the goal of structural innovations is to reduce energy consumption, i.e. $E_{c} \rightarrow 0$, then $I_{Q} \rightarrow \infty$. It follows that the higher the value of the quality index, the finer the product is obtained in process with lower energy consumption.

\subsection{Test stand}

The experiment was conducted on a five-disc mill (Fig. 1).

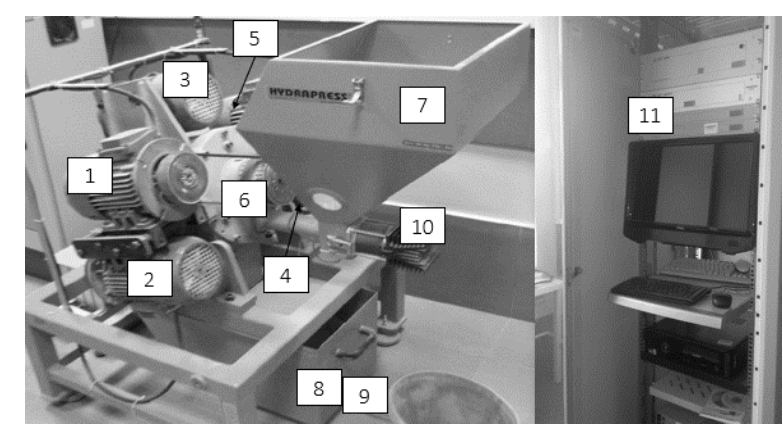

Fig. 1. Multi-disc mill: 1-,2-,3-,4-,5- electric motor, 6- five-disc grinding unit, 7- feeder, 8- basket for grinding product, 9- scale, 10- stepper motor, 11- control unit 
The main elements of the test stand are disc mill, measurement system and control unit. The five-disc mill consists of: a feed chamber, worm feeder, grinding product basket, grinding unit in the form of five discs with holes driven by electric motors. Each disc has own drive motor, which provides to control independently the angular discs speed. The measurement system includes scale for measurement of the product weight, temperature sensors and torque meters.

\subsection{Research plan}

The first step was sieve analysis of the chosen grains to be grinded - rice grains was selected. Then prepared samples were grinded. The angular disc speed was accepted as the variable parameter (Table 1.). Next a sieve analysis of the grinding product was performed with use of digital image processing (CAMSIZER device). Sieve analyzes was done to estimate grains $\bar{D}$ and product particles characteristic size $\bar{d}$ (average size). Last step was a results analysis (Fig. 2.).

Table 1

Configurations of angular discs speed; $V_{p}$ - dosing speed, $\omega_{1}, \omega_{2}, \omega_{3}, \omega_{4}, \omega_{5}$ - discs angular speed, $\Delta \omega-$ angular speed gradient between discs

\begin{tabular}{|c|c|c|c|c|c|c|c|c|}
\hline \multirow{2}{*}{ Case } & \multirow{2}{*}{$\begin{array}{c}\text { No of } \\
\text { config. }\end{array}$} & $V_{p}$ & $\omega_{1}$ & $\omega_{2}$ & $\omega_{3}$ & $\omega_{4}$ & $\omega_{5}$ & $\Delta \omega$ \\
\hline & & $\mathbf{k g} \cdot \mathbf{h}^{-1}$ & $\mathrm{rad} \cdot \mathrm{s}^{-1}$ & $\mathrm{rad} \cdot \mathrm{s}^{-1}$ & $\mathrm{rad} \cdot \mathrm{s}^{-1}$ & $\mathrm{rad} \cdot \mathrm{s}^{-1}$ & $\mathrm{rad} \cdot \mathrm{s}^{-1}$ & $\mathrm{rad} \cdot \mathrm{s}^{-1}$ \\
\hline \multirow{4}{*}{ I } & 1 & \multirow{8}{*}{102} & 20 & 25 & 30 & 35 & 40 & 5 \\
\hline & 2 & & 20 & 30 & 40 & 50 & 60 & 10 \\
\hline & 3 & & 20 & 35 & 50 & 65 & 80 & 15 \\
\hline & 4 & & 20 & 40 & 60 & 80 & 100 & 20 \\
\hline \multirow{4}{*}{ II } & 1 & & 100 & 80 & 60 & 40 & 20 & 20 \\
\hline & 2 & & 80 & 65 & 50 & 35 & 20 & 15 \\
\hline & 3 & & 60 & 50 & 40 & 30 & 20 & 10 \\
\hline & 4 & & 40 & 35 & 30 & 25 & 20 & 5 \\
\hline
\end{tabular}

Source: own work

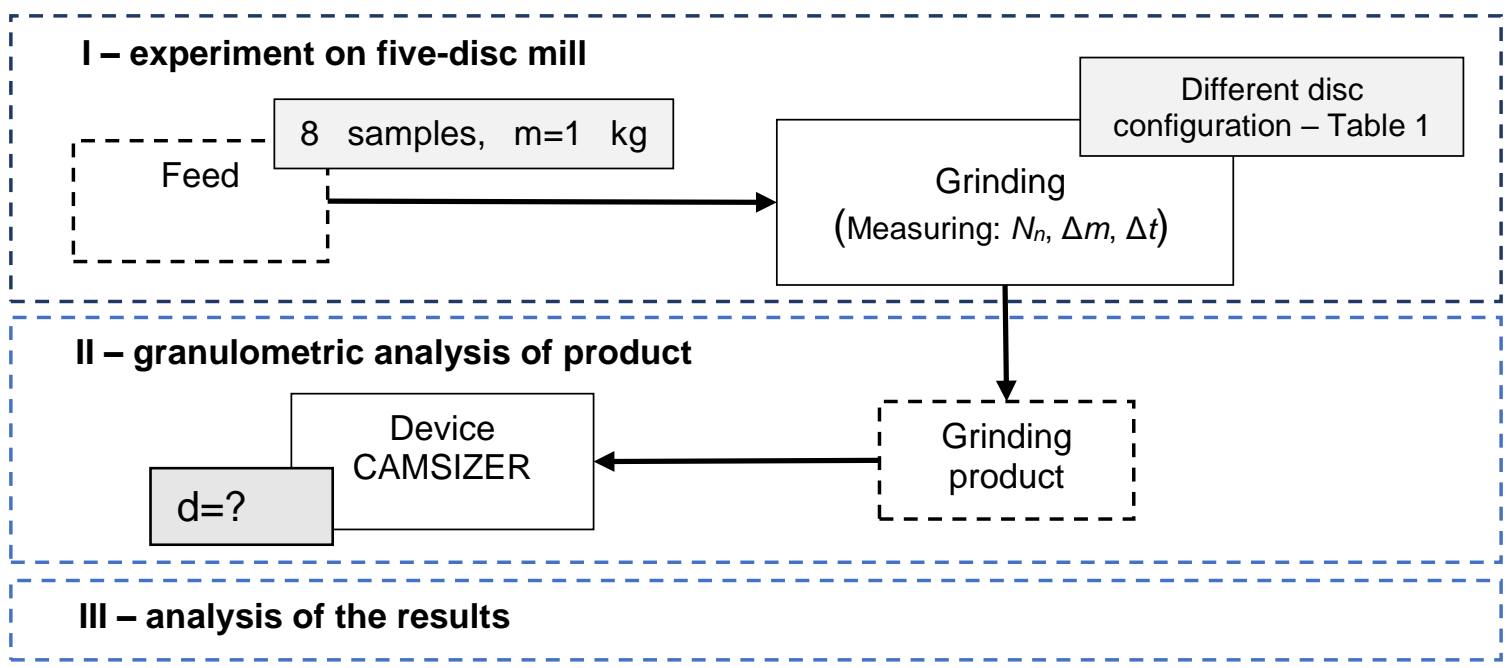

Fig. 2. Research plan 


\section{RESULTS AND DISCUSSION}

In order to verify the quality index of grinding, an experiment was carried out on a fivedisc mill. Table 2 presents the values of the model variables and the calculated quality index. The analysis shows that on the basis of the quality index, the grinding process can be evaluated and compared, as well the settings of the process parameters ensuring the highest quality can be indicated. Among the eight tested settings of discs angular speed, the best settings were found: the fourth of the first case and the first of the second case (Table 2.). It was observed that the discs angular speed affect the value of energy consumption $E_{c}$, dimensional reduction $\Delta S_{r}$ and thus the value of the quality index $I_{Q}$ of the grinding process.

Table 2

Results of the grinding process quality assessment - quality index values; $E_{c}$ - energy consumption per $1 \mathrm{~kg}$ of material, $\bar{D}$ - average feed size, $\Delta S_{r}$ - size reduction of grinded material characteristic dimension, $l_{Q}-$ quality index

\begin{tabular}{|c|c|c|c|c|c|c|}
\hline \multirow{2}{*}{ Case } & \multirow{2}{*}{$\begin{array}{l}\text { No of } \\
\text { config. }\end{array}$} & $E c$ & $\bar{D}$ & $\bar{d}$ & $\Delta S_{r}$ & lo \\
\hline & & $k W h$ & $m m$ & $m m$ & $m m$ & $\mathrm{~mm} / \mathrm{kWh}$ \\
\hline \multirow{4}{*}{ I } & 1 & 0.042 & 1.979 & 1.765 & 0.214 & 5.1 \\
\hline & 2 & 0.053 & 1.965 & 1.619 & 0.346 & 6.6 \\
\hline & 3 & 0.059 & 1.983 & 1.472 & 0.511 & 8.6 \\
\hline & 4 & 0.067 & 1.970 & 1.334 & 0.636 & 9.5 \\
\hline \multirow{4}{*}{ II } & 1 & 0.054 & 1.974 & 1.527 & 0.447 & \begin{tabular}{|l|}
8.2 \\
\end{tabular} \\
\hline & 2 & 0.049 & 1.976 & 1.650 & 0.326 & 6.6 \\
\hline & 3 & 0.043 & 1.969 & 1.700 & 0.269 & 6.3 \\
\hline & 4 & 0.034 & \begin{tabular}{|l|}
1.977 \\
\end{tabular} & 1.780 & 0.197 & 5.8 \\
\hline
\end{tabular}

Source: own work

In order to identify relationships between variables, a Pearson correlation analysis was performed. It showed that energy consumption $E_{c}$, size reduction $\Delta S_{r}$ as well as quality index $I_{Q}$ are strongly positively correlated with the angular speed of disc $3\left(\omega_{3}\right)$ and disc $4\left(\omega_{4}\right)$ as well as the angular speed gradient between discs $\Delta \omega$ (Table 3).

Table 3

Results of correlation analysis between variables - values of $r$-Pearson, $\omega_{1}, \omega_{2}, \omega_{3}, \omega_{4}, \omega_{5}-$ discs angular speed, $\Delta \omega$-speed gradient between discs, $E_{c}$ - energy consumption per $1 \mathrm{~kg}$ of material, $\Delta S_{r}-$ size reduction of grinded material characteristic dimension, $I_{Q}-$ quality index

\begin{tabular}{|l|l|c|c|c|c|c|c|c|c|}
\hline & $\boldsymbol{\omega}_{1}$ & $\boldsymbol{\omega}_{2}$ & $\boldsymbol{\omega}_{3}$ & $\boldsymbol{\omega}_{\mathbf{4}}$ & $\boldsymbol{\omega}_{5}$ & $\boldsymbol{\Delta} \boldsymbol{\omega}$ & $\boldsymbol{E}_{c}$ & $\boldsymbol{\Delta} \boldsymbol{S}_{\mathbf{r}}$ & $\boldsymbol{I}_{\boldsymbol{Q}}$ \\
\hline$E_{c}$ & -0.139 & 0.153 & 0.852 & 0.924 & 0.783 & 0.852 & 1.000 & & \\
\hline$\Delta S_{r}$ & -0.112 & 0.181 & 0.871 & 0.920 & 0.770 & 0.871 & 0.965 & 1.000 & \\
\hline$I_{Q}$ & 0.010 & 0.292 & 0.895 & 0.841 & 0.666 & 0.895 & 0.906 & 0.979 & 1.000 \\
\hline \multicolumn{6}{|c|}{ - } \\
\hline
\end{tabular}

Source: own work

Then regression analysis was performed. In the first step, linear relationships and their degree of matching were checked. Obtained linear models explained the variability of the quality index to a good degree $\left(R^{2}>0.760\right.$; Fig. 3 and Fig. 4). In this case, the variability of the quality index is explained in $80 \%$ by variability of the angular speed of the disc $3\left(\omega_{3}\right)(F<0.05, p<0.05$; Fig. 3$)$. Similar value of $R$-squared statistic was obtained for the relationship between the quality index $I_{Q}$ and the angular 


\section{$\underline{508}$}

speed gradient between discs $\Delta \omega$ (Fig. 4). The variability of the quality index in $70 \%$ was explained by the variation of the angular speed of the disc $4\left(\omega_{4}\right)(F<0.05, p$ $<0.05$, Fig. 3).

In addition, it was checked how the linear model of many variables will describe the quality index variability in case of multi-disc rice grinding. The conducted multiple stepwise regression analysis with backward elimination showed that the best variability of the quality index was described by the model of two variables (over $92 \%$ ) $\omega_{3}$ and $\omega_{4}$ (Table 4, eq. 7).

$$
I_{Q}=0.076 \omega_{3}+0.036 \omega_{4}+2.024 \pm 0,48
$$

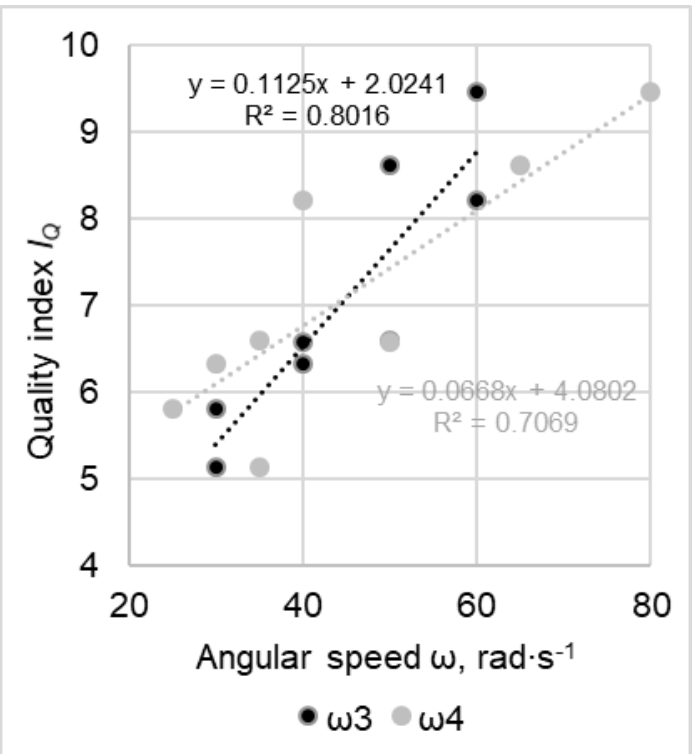

Fig. 3. Graph of the quality index in dependence on the third $\omega_{3}$ and fourth disc $\omega_{4}$ angular speed

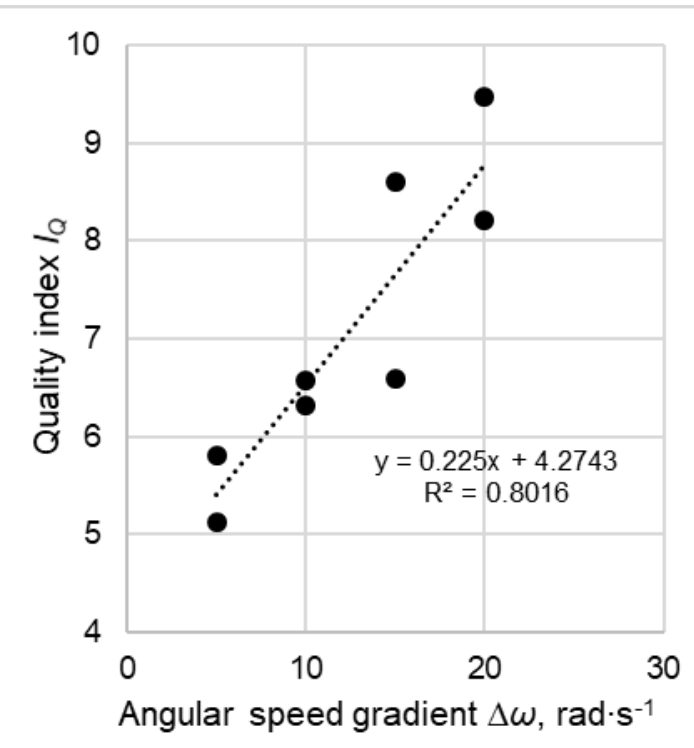

Fig. 4. Graph of the quality index in dependence on angular speed gradient between discs $\Delta \omega$

Table 4.

Results of multiple regression analysis; $\omega_{3}, \omega_{4}$, - discs angular speed, $\operatorname{rad} \cdot \mathrm{s}^{-1}, \Delta \omega$ - angular speed gradient between discs

\begin{tabular}{|l|l|l|l|l|l|l|}
\cline { 2 - 4 } \multicolumn{1}{c|}{} & \multicolumn{1}{c|}{ Coefficient } & \multicolumn{1}{c|}{$\boldsymbol{t}$-value } & $\boldsymbol{p}$-value & $\boldsymbol{F}$ & $\boldsymbol{P}$-value of $\boldsymbol{F}$ & \multicolumn{1}{c|}{$\boldsymbol{R}^{\mathbf{2}}$} \\
\hline constant & 2.024 & 2.879 & 0.034 & & & \\
& 0.076 & 3.890 & 0.012 & \multirow{3}{*}{31.833} & 0.00143 & 0.927 \\
\hline$\omega_{4}$ & 0.036 & 2.936 & 0.032 & & & \\
\hline
\end{tabular}

Source: own work

The obtained regression equation is significant because $P$-value of $F<0.005$ and all coefficients are also considered significant ( $p$-value<0.05) (Table 4.). It was shown that there is a strong correlation $(R=0.96)$ between the value of the quality index and the angular speed of the third $\left(\omega_{3}\right)$ and the fourth $\left(\omega_{4}\right)$ disc. The obtained model of two variables in $92 \%$ explains the variability of the quality index. Based on the analysis of the residuals and the value of the correlation and determination coefficients, it is assumed that the presented regression model fits very good to source data.

On the basis of the results obtained, it was found that the developed quality index can be used to evaluate the process of grinding and its optimization, bearing in mind the quality, the degree of product fragmentation and energy consumption. Analyzes of 
relationships between variables have shown that the process parameters (angular speed of the third and the fourth disc) of multi-disc grinding have a significant impact on the components of the quality model (energy consumption, reduction of particle size) (Table 3). The energy consumption for grinding increases and the product fragmentation is getting better (the product is characterized by a smaller particle size) with the increase of the discs angular speed. Similar dependencies for multi-disc grinding was described, among others, in the papers (Guo et al., 2012; Ismail and Elhenaway, 2009; Smejtkova and Vaculik, 2018). A significant positive correlation between the quality index and the angular speed of the third and the fourth disc as well as the velocity gradient was also shown (Table 3). It follows that as the parameters increase, the quality indicator will also increase.

\section{SUMMARY AND CONCLUSION}

The quality of grinding plays a significant role in assessing the efficiency and effectiveness of the process. Most often, quality analyzes are carried out with reference only to the product quality. This paper presents an original index for the assessment of the grinding process quality combining the product parameters (particle size reduction) with the process parameters (energy consumption). On the basis of the conducted research, it was found that it is possible to build a mathematical model describing the quality of the grinding process, and the experimental verification carried out showed that the developed index can also be used to optimize the grinding process, which is the solution to the first research problem.

On the basis of the results of statistical analyzes, a solution to the second research problem was obtained, i.e. it was found that:

- process parameters such as angular speed of the third and the fourth disc of multi-disc grinding have a significant impact on the components of the quality model (energy consumption, reduction of particle size) (Table 3 and Table 4). The energy consumption for grinding increases and the product fragmentation is getting better (the product is characterized by a smaller particle size) with the increase of the discs angular speed;

- the quality index is positively correlated with the angular speed of the third and the fourth disc and with the speed gradient between discs (Table 3) - the increase of these parameters causes an increase in the quality index.

\section{ACKNOWLEDGEMENTS}

Scientific work financed by the budget resource for science in 2017-2021, as a research project under the "Diamentowy Grant" program.

\section{REFERENCES}

Albuquerque, T., Dias, V. H., Poellinger, N., Pinto, J. F., 2010. Construction of a quality index for granules produced by fluidized bed technology and application of the correspondence analysis as a discriminant procedure, European Journal of Pharmaceutics and Biopharmaceutics, 75 (3), 418-424, DOI: 10.1016/j.ejpb.2010.04.002

Chen, K., Wang, C., Tan, K. H., Chiu, S-F., 2019. Developing one-sided specification six-sigma fuzzy quality index and testing model to measure the process 


\section{$\underline{510}$}

performance of fuzzy information, International Journal of Production Economics, 208, 560-565, DOI: 10.1016/j.jpe.2018.12.025

Coronado-Mendoza, A., Gurubel-Tun, K. J., Zúñiga-Grajeda, V., Domínguez-Navarro, J. A., Artal-Sevil, J. S., 2018. Variable Frequency Control of a Photovoltaic Boost Converter System with Power Quality Indexes Based on Dynamic Phasors, IFACPapersOnLine, 2nd IFAC Conference on Modelling, Identification and Control of Nonlinear Systems MICNON 2018, 51 (13), 180-185, DOI: 10.1016/j.ifacol.2018.07.279

Dal-Pastro, F., Facco, P., Bezzo, F., Thomas, H., Zamprogna, E., Barolo, M., 2015. Data-based multivariate modeling of a grain comminution process, 12 International Symposium on Process Systems Engineering and 25 European Symposium on Computer Aided Process Engineering, Elsevier, 2219-2224, DOI: 10.1016/B978-0444-63576-1.50064-9

Djekic, I., Tomic, N., Bourdoux, S., Spilimbergo, S., Smigic, N., Udovicki, B., Hofland, G., Devlieghere, F., Rajkovic, A., 2018. Comparison of three types of drying (supercritical $\mathrm{CO}_{2}$, air and freeze) on the quality of dried apple - Quality index approach, LWT, 94, 64-72, DOI: 10.1016/j.Iwt.2018.04.029

Flizikowski, J., Kruszelnicka, W., Tomporowski, A., Mrozinski, A., 2019. A study of operating parameters of a roller mill with a new design, AIP Conference Proceedings, 2077 (1), 020018, DOI: 10.1063/1.5091879

Guo, Y., Loenders, J., Duflou, J., Lauwers, B., 2012. Optimization of Energy Consumption and Surface Quality in Finish Turning, Procedia CIRP, 1, 512-517, DOI: 10.1016/j.procir.2012.04.091

$\mathrm{Hu}, \mathrm{J} .$, Chen, Y., Ni, D., 2012. Effect of superfine grinding on quality and antioxidant property of fine green tea powders, LWT - Food Science and Technology, 45 (1), 8-12, DOI: 10.1016/j.Iwt.2011.08.002

Ismail, Z.E., Elhenaway, M. N., 2009. Optimization of Machine Parameters for a Sunflower Thresher Using Friction Drum, Journal of Agricultural Science of Mansoura University, 34 (10), 10293-10304

Kolman, R., 2003. Różne odmiany jakości i ich praktyczne wykorzystanie. PLACET, Warsaw-Poland.

Kruszelnicka, W., Flizikowski, J., Tomporowski, A., 2018. Auto-Monitoring System of Grainy Biomass Comminution Technology, IOP Conference Series: Materials Science and Engineering, 393 (1), 012076, DOI: 10.1088/1757-899X/393/1/012076

Kruszelnicka, W., Tomporowski, A., Flizikowski, J., Kasner, R., Cyganiuk, J., 2019. Basis of biomass grinders sustainable designing, System Safety: Human Technical Facility - Environment 2019, 1(1), 542-549, DOI: 10.2478/czoto-20190069

Kruszelnicka, W., 2018. Multi-disc comminution product quality analysis, Ekologia i Technika, 28 (3), 41-48.

Lasisi, A., Attoh-Okine, N., 2018. Principal components analysis and track quality index: A machine learning approach, Transportation Research Part C: Emerging Technologies, 91, 230-248, DOI: 10.1016/j.trc.2018.04.001

Lee, E., Bisson, J. A., Han, H-S., 2017. Evaluating the production cost and quality of feedstock produced by a sawdust machine, Biomass and Bioenergy, 104, 53-60, DOI: 10.1016/j.biombioe.2017.06.010

Łunarski, J., 2012. Zarządzanie jakością. Standardy i zasady, WNT, Warsaw-Poland. 
Mi, D., Bahnasawy, A., Ali, S., El-Haddad, Z., 2015. Grinding Parameters and Their Effects on the Quality of Corn for Feed Processing, Journal of Food Processing \& Technology, 6 (9), 1-7, DOI: 10.4172/2157-7110.1000482.

Przystupa, F. W., Stryczek, J., Sokolski, P., 2013. Assessment of operation quality of an excavator-jaw crusher system, Górnictwo Odkrywkowe, 54 (3-4), 18-23.

Przystupa, F. W., 2010. Diagnozer w systemie technicznym: od ontologii $i$ aksjologii do praktyki, Oficyna Wydawnicza Politechniki Wrocławskiej, Wrocław-Poland.

Schwechten, D., Milburn, G. H., 1990. Experiences in dry grinding with high compression roller mills for end product quality below 20 microns, Minerals Engineering, 3 (1), 23-34, DOI: 10.1016/0892-6875(90)90078-P

Seifoddini, H., Djassemi, M., 2001. The effect of reliability consideration on the application of quality index, Computers \& Industrial Engineering, 40 (1), 65-77, DOI: 10.1016/S0360-8352(00)00072-3

Smejtkova, A., Vaculik, P., 2018. Comparison of Power Consumption of a Two-Roll Mill and a Disc Mill, Agronomy Research, 16, 1486-1492, DOI: 10.15159/ar.18.017

Tomporowski, A., Flizikowski J., Kruszelnicka, W., 2017. A new concept of roller-plate mills, Przemysł Chemiczny, 96 (8), 1750-1755, DOI: 10.15199/62.2017.8.29

Tomporowski, A., Flizikowski, J., Wełnowski, J., Najzarek, Z., Topoliński, T., Kruszelnicka, W., Piasecka, I., Śmigiel, S., 2018. Regeneration of Rubber Waste Using an Intelligent Grinding System, Przemysł Chemiczny, 97 (10), 61-67, DOI: 10.15199/62.2018.10.6

Williams, O., Lester, E., Kingman, S., Giddings, D., Lormor, S., Eastwick, C., 2017. Benefits of Dry Comminution of Biomass Pellets in a Knife Mill, Biosystems Engineering, 160, 42-54, DOI: 10.1016/j.biosystemseng.2017.05.011 